\title{
Macrofauna epiedáfica em área de cultivo do noni sob práticas de manejo
}

\section{agroecológicas}

\author{
Epiedaphic macrofauna in noni cultivation area under agricultural practices demand \\ Macrofauna epiedáfica en el área de cultivo de noni bajo prácticas de manejo agroecológico
}

Recebido: 04/01/2021 | Revisado: 04/01/2021 | Aceito: 06/01/2021 | Publicado: 08/01/2021

\author{
Amanda Dias Costa \\ ORCID: https://orcid.org/0000-0002-9781-2130 \\ Universidade Federal da Paraíba, Brasil \\ E-mail: costaamandaufpb@gmail.com \\ Raunira da Costa Araújo \\ ORCID: https://orcid.org/0000-0002-8917-8360 \\ Universidade Federal da Paraíba, Brasil \\ E-mail: arinuar@hotmail.com \\ Belísia Lúcia Moreira Toscano Diniz \\ ORCID: https://orcid.org/0000-0002-7580-2433 \\ Universidade Federal da Paraíba, Brasil \\ E-mail: belisia.diniz@gmail.com \\ Solange de Sousa \\ ORCID: https://orcid.org/0000-0002-8587-4828 \\ Universidade Federal da Paraíba, Brasil \\ E-mail: solange_ufpb@yahoo.com.br \\ Thiago do Nascimento Coaracy \\ ORCID: https://orcid.org/0000-0001-6647-7141 \\ Universidade Federal da Paraíba, Brasil \\ E-mail: thiago.coaracy@gmail.com \\ Wedson Aleff Oliveira da Silva \\ ORCID: https://orcid.org/0000-0002-8021-1961 \\ Universidade Estadual da Paraíba, Brasil \\ E-mail: wedsonaleff@gmail.com \\ Maria Monique Tavares Saraiva \\ ORCID: https://orcid.org/0000-0003-1165-6235 \\ Universidade Federal da Paraíba, Brasil \\ E-mail: moniquetavaresaraiva@gmail.com \\ Hyan Matheus Freitas das Neves Silva \\ ORCID: https://orcid.org/0000-0001-9893-5696 \\ Universidade Federal da Paraíba, Brasil \\ E-mail: hyanmatheustcc@gmail.com
}

\begin{abstract}
Resumo
Objetivou-se avaliar a dinâmica da macrofauna epiedáfica numa área sob cultivo de noni (Morinda citrifolia L.) submetido a diferentes práticas de manejo do solo, em duas épocas de coleta. O delineamento experimental utilizado foi em blocos casualizados em esquema fatorial $2 \times 2 \times 4$, com três repetições. Os tratamentos foram constituídos pela combinação dos fatores com e sem consórcio com bananeira, com e sem cobertura do solo com palhada de bananeira, e doses de biofertilizante bovino $\left(0,0 ; 2,5 ; 5,0\right.$ e 7,5 $\mathrm{L}$ planta $\left.{ }^{-1}\right)$. Para a captura da macrofauna epiedáfica, foram utilizadas armadilhas de queda do tipo pitfall, instaladas no período chuvoso (agosto) e seco (novembro) de 2019. A comunidade foi analisada conforme os parâmetros de abundância, frequência, riqueza e diversidade e os dados foram submetidos a análises de variância, agrupamento e correlação linear. A maior abundância e frequência da macrofauna foram encontradas no período seco, mas a maior riqueza e diversidade ocorreram no período chuvoso. Em ambos os períodos de coleta, a predominância foi da ordem Hymenoptera. Os índices de riqueza e diversidade revelaram, no período chuvoso e seco, os valores mais altos, para os tratamentos doses de biofertilizante associados com consórcio ou cobertura. Foram encontrados efeitos significativos dos períodos de coleta sobre a macrofauna e para interação entre consórcio e cobertura. Houve correlação significativa entre Diptera e teores de matéria orgânica. A macrofauna epiedáfica se mostrou uma importante ferramenta de bioindicação em área de cultivo do noni sob diferentes práticas de manejo, em duas épocas de coleta.
\end{abstract}

Palavras-chave: Hymenoptera; Diptera; Armadilha Pitfall; Manejo do solo. 


\begin{abstract}
The objective was to evaluate the dynamics of the epiedaphic macrofauna in an area under noni cultivation (Morinda citrifolia L.) submitted to different soil management practices, in two collection periods. The experimental design used was in randomized blocks in a $2 \times 2 \times 4$ factorial scheme, with three replications. The treatments consisted of a combination of factors with and without intercropping with banana, with and without soil cover with banana straw, and doses of bovine biofertilizer $\left(0.0 ; 2.5 ; 5.0\right.$ and $\left.7.5 \mathrm{~L} \mathrm{plant}^{-1}\right)$. For the capture of the epiedaptic macrofauna, pitfall-type fall traps were installed, installed in the rainy (August) and dry (November) periods of 2019. The community was analyzed according to the parameters of abundance, frequency, wealth and diversity and the data were submitted to analysis of variance, grouping and linear correlation. The highest abundance and frequency of macrofauna were found in the dry season, but the greatest richness and diversity occurred in the rainy season. In both periods of collection, the predominance was of the order Hymenoptera. The indexes of richness and diversity revealed, in the rainy and dry period, the highest values, for the treatments of doses of biofertilizer associated with consortium or cover. Significant effects of the collection periods were found on the macrofauna and for interaction between consortium and cover. There was a significant correlation between Diptera and organic matter content. Epiedaphic macrofauna proved to be an important bioindication tool in noni cultivation areas under different management practices, in two collection periods.
\end{abstract}

Keywords: Hymenoptera; Diptera; Pitfall trap; Soil management.

\title{
Resumen
}

El objetivo fue evaluar la dinámica de la macrofauna epiedáfica en un área de cultivo de noni (Morinda citrifolia L.) sometida a diferentes prácticas de manejo de suelos, en dos períodos de recolección. El diseño experimental utilizado fue en bloques al azar en un esquema factorial de 2 × 2 × 4, con tres repeticiones. Los tratamientos consistieron en una combinación de factores con y sin intercalación con banano, con y sin cobertura del suelo con paja de banano, y dosis de biofertilizante bovino $\left(0.0 ; 2.5 ; 5.0\right.$ y $\left.7.5 \mathrm{~L} \mathrm{planta}^{-1}\right)$. Para la captura de la macrofauna epiedaptica, se utilizaron trampas de caída tipo trampa, instaladas en los períodos lluvioso (agosto) y seco (noviembre) de 2019. sometido a análisis de varianza, agrupación y correlación lineal. La mayor abundancia y frecuencia de macrofauna se encontró en la época seca, pero la mayor riqueza y diversidad ocurrió en la época de lluvias. En ambos períodos de recolección, el predominio fue del orden Hymenoptera. Los índices de riqueza y diversidad revelaron, en el período lluvioso y seco, los valores más altos, para los tratamientos de dosis de biofertilizante asociados a consorcio o cobertura. Se encontraron efectos significativos de los períodos de recolección en la macrofauna y en la interacción entre consorcio y cobertura. Hubo una correlación significativa entre Diptera y el contenido de materia orgánica. La macrofauna epiedáfica resultó ser una importante herramienta de bioindicación en áreas de cultivo de noni bajo diferentes prácticas de manejo, en dos períodos de recolección.

Palabras clave: Himenópteros; Diptera; Trampa de caída; Manejo de suelos.

\section{Introdução}

O solo, além de ser um substrato para desenvolvimento das plantas e produção de alimentos, também é considerado um organismo vivo, pois abriga milhares de animais e micro-organismos. Por estarem no solo, estes animais são chamados de fauna edáfica, a qual inclui milhares de espécies de organismos invertebrados com diferentes tamanhos, que vão de micrômetros, como a microfauna, até metros, como a macrofauna, apresentando ciclos de vida que variam de dias a anos (Brown et al., 2015).

A classificação da fauna do solo pode ser realizada de acordo com o diâmetro corporal. A microfauna é representada pelos organismos que possuem tamanho inferior a $0,2 \mathrm{~mm}$ e compreende os invertebrados aquáticos que vivem na lâmina de água do solo, composta principalmente por nematoides e protozoários; a mesofauna inclui animais entre 0,2 e 2 mm e corresponde a uma diversidade de organismos, tais como ácaros, colêmbolos e enquitreídeos e a macrofauna é representada por organismos com diâmetro corporal maiores que $2 \mathrm{~mm}$, possuindo uma alta diversidade que inclui minhocas, térmitas, diplópodes, entre outros (Correia et al., 2002; Moço et al., 2005; Baretta et al., 2011).

A macrofauna, em especial para este estudo, desempenha uma importante função no crescimento vegetal, uma vez que contribui para a manutenção da matéria orgânica, influenciando na formação da estrutura do solo por meio da melhoria de suas propriedades físicas (Baretta et al., 2011; Oliveira-Filho et al., 2016; Pompeo et al., 2016).

A população de organismos do solo mostra-se sensível às variações ocorridas nos ambientes, sejam essas biológicas, 
físicas ou químicas, como resultantes do emprego de práticas de manejo do solo e cultivo. O impacto das práticas desenvolvidas no ambiente pode ser expresso por meio da frequência de determinadas populações, influenciando no aumento ou decréscimo da diversidade dos organismos edáficos. Dessa forma, a biota do solo, como fração sensível às mudanças, tem papel importante nas atividades antrópicas, se apresentando como propriedade indicativa para monitorar a qualidade do solo (Baretta, et al., 2011).

Alguns autores (Ludwig et al., 2012; Cabrera, 2012; Socarrás, 2013; Martínez, 2016; Lima et al., 2017; NogueraTalavera et al., 2017) afirmam que a fauna edáfica é considerada um bioindicador de excelente qualidade, pois esses organismos apresentam notável sensibilidade às práticas de manejo, à origem da cobertura vegetal e às mudanças sazonais.

Dessa forma, objetivou-se no estudo, avaliar a dinâmica da macrofauna epiedáfica numa área sob cultivo de noni (Morinda citrifolia L.) submetido a diferentes práticas de manejo do solo, em duas épocas de coleta.

\section{Metodologia}

O estudo foi desenvolvido com uma abordagem quantitativa experimental, conforme Pereira et al. (2018), em um experimento já instalado em campo com a cultura do noni, localizado na Universidade Federal da Paraíba (UFPB), Campus III, Bananeiras-PB, entre fevereiro a novembro de 2019, em delineamento em blocos casualizados, em esquema fatorial 2 × 2 × 4 , com três repetições. Os tratamentos foram resultados da combinação de consórcio (sem e com consórcio com bananeira, cultivar BRS Vitória), cobertura do solo (sem e com cobertura com palhada de bananeira) e doses de biofertilizante de esterco bovino (0,0 L; 2,5 L; 5,0 L; 7,5 L planta $\left.^{-1}\right)$.

As parcelas foram constituídas por duas plantas de noni no cultivo solteiro e duas plantas de noni e uma de bananeira no cultivo consorciado. Os fatores utilizados foram os seguintes: CONS $(\mathrm{C})=$ consórcio $(\mathrm{sem}=0$ e com $=1) ; \operatorname{COB}(\mathrm{C})=$ cobertura $($ sem $=0$ e com $=1)$ e; $\mathrm{BIO}(\mathrm{B})=$ doses de biofertilizante $\left(0,0 ; 2,5 ; 5,0\right.$ e 7,5 L). Tratamentos: $\mathrm{T}_{1}=\mathrm{C}_{0} \mathrm{C}_{0} \mathrm{~B}_{0 \mathrm{~L}} ; \mathrm{T}_{2}=$ $\mathrm{C}_{0} \mathrm{C}_{0} \mathrm{~B}_{2,5 \mathrm{~L}} ; \mathrm{T}_{3}=\mathrm{C}_{0} \mathrm{C}_{0} \mathrm{~B}_{5,0 \mathrm{~L}} ; \mathrm{T}_{4}=\mathrm{C}_{0} \mathrm{C}_{0} \mathrm{~B}_{7,5 \mathrm{~L}} ; \mathrm{T}_{5}=\mathrm{C}_{0} \mathrm{C}_{1} \mathrm{~B}_{0 \mathrm{~L}} ; \mathrm{T}_{6}=\mathrm{C}_{0} \mathrm{C}_{1} \mathrm{~B}_{2,5 \mathrm{~L}} ; \mathrm{T}_{7}=\mathrm{C}_{0} \mathrm{C}_{1} \mathrm{~B}_{5,0 \mathrm{~L}} ; \mathrm{T}_{8}=\mathrm{C}_{0} \mathrm{C}_{1} \mathrm{~B}_{7,5 \mathrm{~L}} ; \mathrm{T}_{9}=\mathrm{C}_{1} \mathrm{C}_{0} \mathrm{~B}_{0 \mathrm{~L}} ; \mathrm{T}_{10}=$ $\mathrm{C}_{1} \mathrm{C}_{0} \mathrm{~B}_{2,5 \mathrm{~L}} ; \mathrm{T}_{11}=\mathrm{C}_{1} \mathrm{C}_{0} \mathrm{~B}_{5,0 \mathrm{~L}} ; \mathrm{T}_{12}=\mathrm{C}_{1} \mathrm{C}_{0} \mathrm{~B}_{7,5 \mathrm{~L}} ; \mathrm{T}_{13}=\mathrm{C}_{1} \mathrm{C}_{1} \mathrm{~B}_{0 \mathrm{~L}} ; \mathrm{T}_{14}=\mathrm{C}_{1} \mathrm{C}_{1} \mathrm{~B}_{2,5 \mathrm{~L}} ; \mathrm{T}_{15}=\mathrm{C}_{1} \mathrm{C}_{1} \mathrm{~B}_{5,0 \mathrm{~L}} ; \mathrm{T}_{16}=\mathrm{C}_{1} \mathrm{C}_{1} \mathrm{~B}_{7,5 \mathrm{~L}}$.

Para a captura da macrofauna epiedáfica, foram utilizadas armadilhas de queda do tipo pitfall que consistem em recipientes plásticos de $500 \mathrm{~mL}$ com cobertura de proteção e solução conservante. Para este estudo, foram utilizadas como recipiente garrafas de polietileno tereftalato (PET), que possuem em média $10 \mathrm{~cm}$ de diâmetro, cortadas na altura de $15 \mathrm{~cm}$. A proteção utilizada foi confeccionada com palitos de madeira e pratos plásticos rasos de $18 \mathrm{~cm}$ de diâmetro. O recipiente foi preenchido com $200 \mathrm{~mL}$ de solução de detergente neutro a $2 \%$, utilizado na água para a quebra da tensão superficial e preservação da fauna (Aquino et al., 2006).

Para instalação das armadilhas, foram abertos orifícios nos pontos de amostragem com auxílio de ferramenta boca-delobo, com largura e profundidade suficientes para encaixar o recipiente de coleta, sendo inserido de forma que a borda do recipiente ficasse nivelada com a superfície do solo, evitando-se a entrada de resíduos de solo no pote, de modo a evitar dificuldades na triagem. Após isso, a solução conservante foi inserida nos recipientes e, em seguida, a cobertura de proteção, fator esse essencial para evitar que a solução dilua ou transborde após uma chuva (Aquino et al., 2006).

Foram inseridas 48 armadilhas, referentes ao número total de parcelas, no período chuvoso (agosto) e seco (novembro) de 2019. Em ambas as instalações, as armadilhas permaneceram no campo por 96 horas. Após esse tempo, foram retiradas do solo e, ainda, em campo, o conteúdo de cada pitfall foi transferido imediatamente para outros recipientes com tampa, os quais foram identificados e transportados para o Laboratório de Entomologia da UFPB, Campus III. 
No laboratório, cada amostra foi vertida em peneira de malha fina para lavagem dos espécimes coletados e, em seguida, transferidos para placas de Petri. A identificação dos espécimes foi realizada ao nível de ordem com auxílio de microscópio estereoscópio.

A comunidade foi analisada conforme os parâmetros de 1) Abundância: número total de espécimes; 2) Frequência (F): proporção de indivíduos de uma espécie em relação ao total de indivíduos da amostra; 3) Riqueza (S): número total de espécies observadas na comunidade, no caso deste estudo, o número de ordens e 4) Diversidade: índice de Shannon-Wiener (H): considera o mesmo peso para espécies raras e abundantes (Shannon \& Weaver, 1949); índice de Simpson (Ds): mede a probabilidade dos espécimes escolhidos ao acaso na mesma comunidade pertencerem a mesma espécie (Simpson, 1949) e Equitabilidade de Pielou (J): calcula o tamanho da diversidade observada em relação à máxima diversidade que se espera (Pielou, 1975); por meio do software PAST 3.0 (PAleontological STatistics) (Hammer, Harper, \& Ryan, 2001).

Foi realizada análise de agrupamento por meio do software PAST 3.0 e análise de correlação linear simples entre as ordens observadas e os atributos do solo, por meio do software Statistic (Statsoft, versão 3.0). Os dados de abundância da fauna do solo nos diferentes tratamentos foram transformados em $\sqrt{X}$ pelo software $\mathrm{R}$, e após isso, submetidos à análise de variância e de regressão para as doses de biofertilizante de esterco bovino, enquanto as médias de consórcio, cobertura e períodos foram comparadas pelo teste $\mathrm{F}$.

\section{Resultados e Discussão}

Foram coletados 1.399 espécimes da macrofauna epiedáfica no período chuvoso e 2.715 no período seco, totalizando 4.114 exemplares. Hymenoptera foi a ordem mais representativa no período chuvoso (82\%), com predominância da família Formicidae, seguida de Aracnídeos (6\%) e Hemiptera (5\%) (Figura 1 e Tabela 1). No período seco, apenas a ordem Hymenoptera teve grande representação com 97\% (Figura 2 e Tabela 1).

Figura 1 - Valores obtidos para número de espécimes por ordem, capturados pela armadilha pitfall na cultura do noni no período chuvoso.

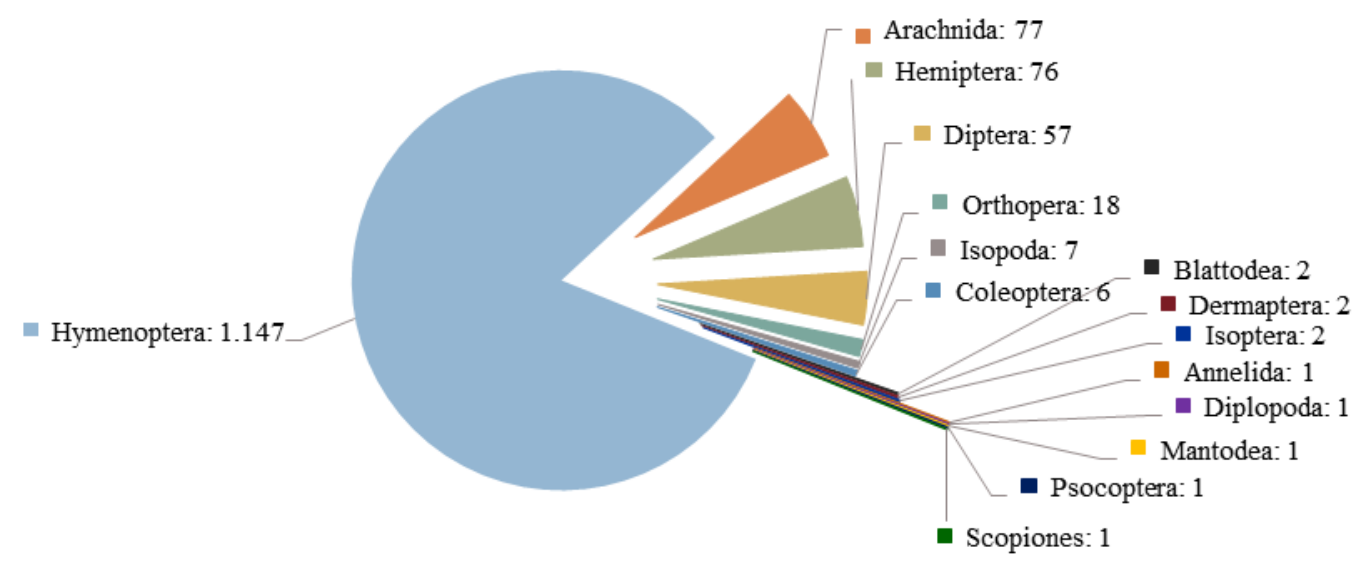

Fonte: Autores.

Na Figura 1 é importante visualizar a predominância da ordem Hymenoptera, representada no gráfico pela cor azul com 1.147 espécimes, seguido de Arachnida com 77, representado pela cor laranja, e Hemiptera com 76 na cor verde. 
Tabela 1 - Número (n) e frequência (F) de indivíduos capturados pela armadilha pitfall na cultura do noni sob consórcio (sem e com), cobertura (sem e com) e doses de biofertilizante de esterco bovino $\left(0,0 ; 2,5 ; 5,0\right.$ e 7,5 $\left.\mathrm{L}_{\text {planta }}{ }^{-1}\right)$ no período chuvoso e seco, Bananeiras-PB, CCHSA, Brasil, 2020.

\begin{tabular}{|c|c|c|c|c|c|c|c|c|c|c|c|c|c|c|c|c|c|c|c|c|}
\hline \multicolumn{3}{|c|}{ Fatores $^{1}$} & Trat. $^{2}$ & \multicolumn{15}{|c|}{ Ordem $^{3}$} & \multicolumn{2}{|c|}{ Trat } \\
\hline CONS & $\mathrm{COB}$ & $\mathrm{BIO}$ & & 1 & 2 & 3 & 4 & 5 & 6 & 7 & 8 & 9 & 10 & 11 & 12 & 13 & 14 & 15 & $\sum_{\mathrm{n}}$ & $\mathrm{F}(\%)$ \\
\hline \multirow{9}{*}{$\sum_{\substack{\sim \\
\sim}}$} & & & & \multicolumn{17}{|c|}{---- Período Chuvoso ---- } \\
\hline & & $0 \mathrm{~L}$ & $\mathrm{~T} 1$ & 1 & 3 & 0 & 0 & 0 & 0 & 1 & 9 & 94 & 0 & 0 & 0 & 0 & 0 & 0 & 108 & 7,7 \\
\hline & $\sum$ & $2,5 \mathrm{~L}$ & $\mathrm{~T} 2$ & 0 & 3 & 0 & 0 & 0 & 0 & 3 & 10 & 129 & 1 & 0 & 0 & 2 & 0 & 0 & 148 & 10,6 \\
\hline & 崩 & $5,0 \mathrm{~L}$ & $\mathrm{~T} 3$ & 0 & 6 & 0 & 0 & 0 & 0 & 2 & 8 & 103 & 0 & 0 & 0 & 0 & 0 & 0 & 119 & 8,5 \\
\hline & & $7,5 \mathrm{~L}$ & $\mathrm{~T} 4$ & 0 & 8 & 0 & 0 & 0 & 0 & 2 & 5 & 143 & 0 & 0 & 0 & 0 & 1 & 0 & 159 & 11,4 \\
\hline & & $0 \mathrm{~L}$ & T5 & 0 & 5 & 0 & 0 & 0 & 0 & 1 & 5 & 69 & 0 & 1 & 1 & 1 & 0 & 0 & 83 & 5,9 \\
\hline & $\sum$ & $2,5 \mathrm{~L}$ & T6 & 0 & 9 & 2 & 0 & 0 & 0 & 5 & 0 & 61 & 0 & 0 & 0 & 1 & 0 & 1 & 79 & 5,6 \\
\hline & U & $5,0 \mathrm{~L}$ & $\mathrm{~T} 7$ & 0 & 10 & 0 & 0 & 0 & 0 & 3 & 3 & 81 & 0 & 0 & 0 & 3 & 0 & 0 & 100 & 7,1 \\
\hline & & 7,5 L & $\mathrm{T} 8$ & 0 & 4 & 0 & 1 & 0 & 0 & 2 & 6 & 38 & 0 & 0 & 0 & 1 & 0 & 0 & 52 & 3,7 \\
\hline \multirow{8}{*}{$\sum_{0}$} & & $0 \mathrm{~L}$ & T9 & 0 & 2 & 0 & 0 & 0 & 0 & 0 & 17 & 14 & 1 & 0 & 0 & 1 & 0 & 0 & 35 & 2,5 \\
\hline & $\sum$ & $2,5 \mathrm{~L}$ & T10 & 0 & 5 & 0 & 2 & 2 & 1 & 6 & 1 & 53 & 4 & 0 & 0 & 2 & 0 & 0 & 76 & 5,4 \\
\hline & $\sqrt[I]{\Omega}$ & $5,0 \mathrm{~L}$ & $\mathrm{~T} 11$ & 0 & 7 & 0 & 1 & 0 & 0 & 16 & 0 & 63 & 0 & 0 & 0 & 0 & 0 & 0 & 87 & 6,2 \\
\hline & & $7,5 \mathrm{~L}$ & $\mathrm{~T} 12$ & 0 & 5 & 0 & 0 & 0 & 0 & 3 & 5 & 97 & 0 & 0 & 0 & 0 & 0 & 0 & 110 & 7,9 \\
\hline & & $0 \mathrm{~L}$ & T13 & 0 & 4 & 0 & 0 & 0 & 0 & 5 & 2 & 93 & 0 & 1 & 0 & 2 & 0 & 0 & 107 & 7,6 \\
\hline & $\sum$ & $2,5 \mathrm{~L}$ & T14 & 0 & 0 & 0 & 1 & 0 & 0 & 2 & 2 & 37 & 0 & 0 & 0 & 2 & 0 & 0 & 44 & 3,1 \\
\hline & ن & $5,0 \mathrm{~L}$ & T15 & 0 & 6 & 0 & 0 & 0 & 0 & 4 & 2 & 51 & 1 & 0 & 0 & 2 & 0 & 0 & 66 & 4,7 \\
\hline & & 7,5 L & T16 & 0 & 0 & 0 & 1 & 0 & 0 & 2 & 1 & 21 & 0 & 0 & 0 & 1 & 0 & 0 & 26 & 1,9 \\
\hline \multirow{9}{*}{$\sum_{\text {贡 }}$} & \multirow{5}{*}{ 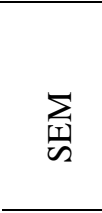 } & & & \multicolumn{17}{|c|}{---- Período Seco ---- } \\
\hline & & $0 \mathrm{~L}$ & $\mathrm{~T} 1$ & 0 & 3 & 0 & 0 & 1 & 0 & 0 & 1 & 140 & 0 & 0 & 0 & 1 & 0 & 0 & 146 & 5,4 \\
\hline & & $2,5 \mathrm{~L}$ & $\mathrm{~T} 2$ & 0 & 5 & 0 & 1 & 0 & 0 & 0 & 1 & 206 & 0 & 0 & 0 & 2 & 0 & 0 & 215 & 7,9 \\
\hline & & $5,0 \mathrm{~L}$ & $\mathrm{~T} 3$ & 0 & 3 & 0 & 0 & 0 & 0 & 0 & 2 & 287 & 0 & 0 & 0 & 0 & 0 & 0 & 292 & 10,8 \\
\hline & & $7,5 \mathrm{~L}$ & $\mathrm{~T} 4$ & 0 & 2 & 0 & 1 & 0 & 0 & 0 & 1 & 427 & 0 & 0 & 0 & 2 & 0 & 0 & 433 & 15,9 \\
\hline & \multirow{4}{*}{$\sum_{\circlearrowright}$} & $0 \mathrm{~L}$ & T5 & $\mathrm{O}$ & 2 & 0 & 3 & 0 & 0 & 0 & 0 & 151 & 0 & 0 & 0 & 0 & 0 & 0 & 156 & 5,7 \\
\hline & & $2,5 \mathrm{~L}$ & T6 & 0 & 1 & 0 & 0 & 0 & 0 & 0 & 0 & 70 & 0 & 0 & 0 & 0 & 0 & 0 & 71 & 2,6 \\
\hline & & $5,0 \mathrm{~L}$ & $\mathrm{~T} 7$ & 0 & 6 & 0 & 0 & 1 & 0 & 0 & 3 & 92 & 0 & 0 & 0 & 1 & 0 & 0 & 103 & 3,8 \\
\hline & & 7,5 L & $\mathrm{T} 8$ & 0 & 5 & 0 & 0 & 0 & 0 & 0 & 0 & 99 & 1 & 0 & 0 & 0 & 0 & 0 & 105 & 3,9 \\
\hline \multirow{8}{*}{$\sum_{0}$} & \multirow{4}{*}{ 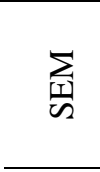 } & $0 \mathrm{~L}$ & T9 & 0 & 1 & 0 & 0 & 0 & 0 & 0 & 1 & 95 & 0 & 0 & 1 & 0 & 0 & 0 & 98 & 3,6 \\
\hline & & $2,5 \mathrm{~L}$ & T10 & 0 & 0 & 0 & 1 & 0 & 0 & 1 & 0 & 128 & 0 & 0 & 0 & 0 & 0 & 0 & 130 & 4,8 \\
\hline & & $5,0 \mathrm{~L}$ & T11 & 0 & 2 & 0 & 1 & 0 & 0 & 0 & 1 & 154 & 0 & 0 & 0 & 1 & 0 & 0 & 159 & 5,9 \\
\hline & & 7,5 L & T12 & 0 & 1 & 0 & 0 & 0 & 0 & 0 & 0 & 187 & 0 & 0 & 0 & 0 & 0 & 0 & 188 & 6,9 \\
\hline & \multirow{4}{*}{$\sum_{0}$} & $0 \mathrm{~L}$ & T13 & 0 & 2 & 0 & 0 & 0 & 0 & 0 & 1 & 185 & 0 & 0 & 0 & 0 & 0 & 0 & 188 & 6,9 \\
\hline & & $2,5 \mathrm{~L}$ & T14 & 0 & 4 & 0 & 1 & 1 & 0 & 0 & 0 & 174 & 0 & 0 & 0 & 0 & 0 & 0 & 180 & 6,6 \\
\hline & & $5,0 \mathrm{~L}$ & T15 & 0 & 4 & 0 & 0 & 0 & 0 & 0 & 0 & 94 & 0 & 0 & 0 & 0 & 0 & 0 & 98 & 3,6 \\
\hline & & $7,5 \mathrm{~L}$ & T16 & 0 & 4 & 0 & 1 & 0 & 0 & 0 & 1 & 146 & 0 & 0 & 1 & 0 & 0 & 0 & 153 & 5,6 \\
\hline \multirow{4}{*}{ Período } & & Churos & $\mathrm{n}$ & 1 & 77 & 2 & 6 & 2 & 1 & 57 & 76 & 1147 & 7 & 2 & 1 & 18 & 1 & 1 & 1399 & 34,0 \\
\hline & & Cnuvoso & $\mathrm{F}(\%)$ & 0,1 & 5,5 & 0,1 & 0,4 & 0,1 & 0,1 & 4,1 & 5,4 & 82,0 & 0,5 & 0,1 & 0,1 & 1,3 & 0,1 & 0,1 & & \\
\hline & & & $\mathrm{n}$ & $\mathrm{O}$ & 45 & $\mathrm{o}$ & 9 & 3 & o & 1 & 12 & 2635 & 1 & o & 2 & 7 & $\mathrm{o}$ & o & 2715 & 66,0 \\
\hline & & Seco & $\mathrm{F}(\%)$ & 0,0 & 1,7 & 0,0 & 0,3 & 0,1 & 0,0 & 0,0 & 0,4 & 97,1 & 0,0 & 0,0 & 0,1 & 0,3 & 0,0 & 0,0 & & \\
\hline
\end{tabular}

${ }^{1}$ Fatores: CONS = consórcio ( $\left(0,0 ; 2,5 ; 5,0\right.$ e 7,5 L); ${ }^{2}$ Tratamentos: $\mathrm{T}_{1}=\mathrm{C}_{0} \mathrm{C}_{0} \mathrm{~B}_{0 \mathrm{~L}} ; \mathrm{T}_{2}=\mathrm{C}_{0} \mathrm{C}_{0} \mathrm{~B}_{2,5 \mathrm{~L}} ; \mathrm{T}_{3}=\mathrm{C}_{0} \mathrm{C}_{0} \mathrm{~B}_{5,0 \mathrm{~L}} ; \mathrm{T}_{4}=\mathrm{C}_{0} \mathrm{C}_{0} \mathrm{~B}_{7,5 \mathrm{~L}} ; \mathrm{T}_{5}=\mathrm{C}_{0} \mathrm{C}_{1} \mathrm{~B}_{0 \mathrm{~L}} ; \mathrm{T}_{6}=\mathrm{C}_{0} \mathrm{C}_{1} \mathrm{~B}_{2,5 \mathrm{~L}} ; \mathrm{T}_{7}=$ $\mathrm{C}_{0} \mathrm{C}_{1} \mathrm{~B}_{5,0 \mathrm{~L}} ; \mathrm{T}_{8}=\mathrm{C}_{0} \mathrm{C}_{1} \mathrm{~B}_{7,5 \mathrm{~L}} ; \mathrm{T}_{9}=\mathrm{C}_{1} \mathrm{C}_{0} \mathrm{~B}_{0 \mathrm{~L}} ; \mathrm{T}_{10}=\mathrm{C}_{1} \mathrm{C}_{0} \mathrm{~B}_{2,5 \mathrm{~L}} ; \mathrm{T}_{11}=\mathrm{C}_{1} \mathrm{C}_{0} \mathrm{~B}_{5,0 \mathrm{~L}} ; \mathrm{T}_{12}=\mathrm{C}_{1} \mathrm{C}_{0} \mathrm{~B}_{7,5 \mathrm{~L}} ; \mathrm{T}_{13}=\mathrm{C}_{1} \mathrm{C}_{1} \mathrm{~B}_{0 \mathrm{~L}} ; \mathrm{T}_{14}=\mathrm{C}_{1} \mathrm{C}_{1} \mathrm{~B}_{2,5 \mathrm{~L}} ; \mathrm{T}_{15}=\mathrm{C}_{1} \mathrm{C}_{1} \mathrm{~B}_{5,0 \mathrm{~L}} ;$ $\mathrm{T}_{16}=\mathrm{C}_{1} \mathrm{C}_{1} \mathrm{~B}_{7,5 \mathrm{~L}} .{ }^{3}$ Ordem: $1=$ Annelida; 2 = Arachnida; $3=$ Blattodea; $4=$ Coleoptera; $5=$ Dermaptera; $6=$ Diplopoda; $7=$ Diptera; $8=$ Hemiptera; 9 = Hymenoptera; $10=$ Isopoda; $11=$ Isoptera; $12=$ Mantodea; $13=$ Orthopera; $14=$ Psocoptera e $15=$ Scorpiones.

Fonte: Autores.

Na Tabela 1, também é possível visualizar essa distribuição, onde na linha período, estão descritos o número e frequência de espécimes por ordem nas fases chuvosa e seca.

Figura 2 - Valores obtidos para número de espécimes por ordem, capturados pela armadilha pitfall na cultura do noni no período seco. 


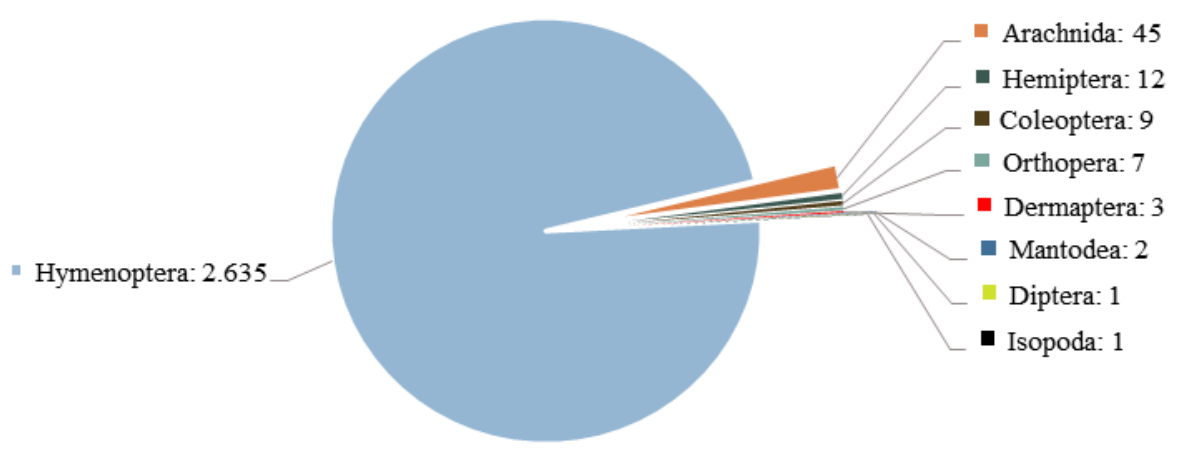

Fonte: Autores.

A Figura 2 apresenta de forma clara apenas a predominância da ordem Hymenoptera (cor azul) no período seco (n = 2.635), em comparação as demais ordens.

Isso pode estar diretamente relacionado ao período de coleta, pois a época seca pode provocar desfolha natural nas culturas, permitindo um desenvolvimento abundante de determinados insetos, em especial, formigas desfolhadoras (Figueiredo, 2001). Contudo, de acordo com Lavelle e Spain (2001), a alta abundância deste grupo não deve estar sempre relacionada com prejuízos à agricultura, pois a maior parte dos grupos da família Formicidae não são desfolhadoras e possuem um papel importante na manutenção da qualidade do solo, configurando úteis bioindicadores do ambiente.

Além disso, esse grupo possui adaptações para as condições de época seca, estando presente em condições ecossistêmicas adversas, em comparação com outros grupos. O estudo realizado por Nunes et al. (2012), em um Latossolo Amarelo distrófico com textura franco-arenosa, revelou predominância deste grupo em condições de deficit hídrico.

Considerando a importância funcional, na classe Insecta, Hymenoptera se apresenta como um dos maiores grupos, incluindo vespas, abelhas e formigas e a atuação desses organismos no solo compreende escavação e/ou ingestão e transporte de matéria mineral e orgânica, promovendo a construção de estruturas biogênicas que atuam na agregação e aeração do solo, dinâmica da matéria orgânica, atributos hidráulicos, banco de sementes, além da composição, frequência e diversidade de outros organismos no ambiente terrestre (Crepaldi et al., 2014).

Resultados semelhantes foram obtidos a partir do uso de armadilhas de queda do tipo Pitfall em diferentes agroecossistemas nas regiões de Sergipe (Dantas et al., 2012), Bahia (Pereira \& Carvalho, 2011), Acre (Santos et al., 2016), Pará (Rodrigues et al., 2016), Distrito Federal (Prado \& Castro, 2017) e Goiás (Alonso et al., 2017), havendo predominância dos espécimes da ordem Hymenoptera, o que comprova a relevância desse grupo em diferentes regiões, independente da metodologia empregada.

O índice de riqueza foi maior no período chuvoso, com a presença de 15 ordens, em comparação ao período seco que obteve o total de 9 ordens, bem como a diversidade, que também apresentou maiores valores no período chuvoso (Tabela 2). Portanto, embora uma maior abundância e frequência tenha sido encontrada no período seco, uma maior riqueza e diversidade de ordens pôde ser observada na fase chuvosa, corroborando com o estudo de Nunes et al. (2012), que, ao avaliarem a distribuição da fauna de diferentes sistemas de manejo, nas épocas chuvosa e seca, observaram maiores valores de riqueza, diversidade e uniformidade de fauna na amostragem realizada no período úmido, em detrimento das amostras feitas no período seco, que apresentaram maiores valores de abundância, em especial para Hymenoptera. 
Tabela 2 - Riqueza (s), índices de Simpson $\left(D_{S}\right)$, Shannon-Wiener $(H)$ e equitabilidade de Pielou $(J)$ de indivíduos capturados pela armadilha pitfall na cultura do noni sob consórcio (sem e com), cobertura (sem e com) e doses de biofertilizante de esterco bovino $(0,0 ; 2,5 ; 5,0$ e 7,5 L) no período chuvoso e seco, Bananeiras-PB, CCHSA, Brasil, 2020.

\begin{tabular}{|c|c|c|c|c|c|c|c|}
\hline \multicolumn{3}{|c|}{ Fatores $^{1}$} & \multirow{2}{*}{ Trat. $^{2}$} & \multirow{2}{*}{$\mathrm{S}$} & \multirow{2}{*}{$\mathrm{D}_{\mathrm{S}}$} & \multirow{2}{*}{$\mathrm{H}$} & \multirow{2}{*}{$\mathrm{J}$} \\
\hline CONS & $\mathrm{COB}$ & $\mathrm{BIO}$ & & & & & \\
\hline \multirow{9}{*}{$\sum_{\sqrt[\Omega]{\sim}}$} & \multirow{5}{*}{$\sum_{\sqrt{\sim 1}}$} & & \multicolumn{5}{|c|}{--- Período Chuvoso --- } \\
\hline & & $0 \mathrm{~L}$ & $\mathrm{~T} 1$ & 5 & 0,2346 & 0,5142 & 0,3195 \\
\hline & & $2,5 \mathrm{~L}$ & $\mathrm{~T} 2$ & 6 & 0,2347 & 0,5518 & 0,3080 \\
\hline & & $5,0 \mathrm{~L}$ & $\mathrm{~T} 3$ & 4 & 0,2435 & 0,5258 & 0,3793 \\
\hline & & $7,5 \mathrm{~L}$ & $\mathrm{~T} 4$ & 5 & 0,1874 & 0,4415 & 0,2743 \\
\hline & \multirow{4}{*}{$\sum_{0}$} & $0 \mathrm{~L}$ & T5 & 7 & 0,3011 & 0,7050 & 0,3623 \\
\hline & & $2,5 \mathrm{~L}$ & T6 & 6 & 0,3858 & 0,8255 & 0,4607 \\
\hline & & $5,0 \mathrm{~L}$ & $\mathrm{~T} 7$ & 5 & 0,3312 & 0,7165 & 0,4452 \\
\hline & & $7,5 \mathrm{~L}$ & T8 & 6 & 0,4445 & 0,9530 & 0,5319 \\
\hline \multirow{8}{*}{$\sum_{0}$} & \multirow{4}{*}{$\sum_{\sqrt[S]{\sim}}$} & $0 \mathrm{~L}$ & T9 & 5 & 0,5992 & 1,0840 & 0,6735 \\
\hline & & $2,5 \mathrm{~L}$ & $\mathrm{~T} 10$ & 9 & 0,4979 & 1,1870 & 0,5402 \\
\hline & & $5,0 \mathrm{~L}$ & $\mathrm{~T} 11$ & 4 & 0,4352 & 0,7992 & 0,5765 \\
\hline & & $7,5 \mathrm{~L}$ & $\mathrm{~T} 12$ & 4 & 0,2175 & 0,4901 & 0,3536 \\
\hline & \multirow{4}{*}{$\sum_{0}$} & $0 \mathrm{~L}$ & T13 & 6 & 0,2402 & 0,5803 & 0,3239 \\
\hline & & $2,5 \mathrm{~L}$ & $\mathrm{~T} 14$ & 5 & 0,2862 & 0,6532 & 0,4059 \\
\hline & & $5,0 \mathrm{~L}$ & $\mathrm{~T} 15$ & 6 & 0,3889 & 0,8625 & 0,4814 \\
\hline & & $7,5 \mathrm{~L}$ & $\mathrm{~T} 16$ & 5 & 0,3373 & 0,7457 & 0,4634 \\
\hline \multirow{9}{*}{$\sum_{\sqrt[\Omega]{\sim}}$} & \multirow{5}{*}{ 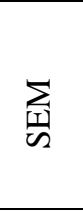 } & & \multicolumn{5}{|c|}{--- Período Seco --- } \\
\hline & & $0 \mathrm{~L}$ & $\mathrm{~T} 1$ & 5 & 0,0799 & 0,2225 & 0,1382 \\
\hline & & $2,5 \mathrm{~L}$ & $\mathrm{~T} 2$ & 5 & 0,0813 & 0,2219 & 0,1379 \\
\hline & & $5,0 \mathrm{~L}$ & $\mathrm{~T} 3$ & 3 & 0,0338 & 0,0982 & 0,0893 \\
\hline & & $7,5 \mathrm{~L}$ & $\mathrm{~T} 4$ & 5 & 0,0275 & 0,0915 & 0,0568 \\
\hline & \multirow{4}{*}{$\sum_{0}$} & $0 \mathrm{~L}$ & T5 & 3 & 0,0625 & 0,1634 & 0,1487 \\
\hline & & $2,5 \mathrm{~L}$ & T6 & 2 & 0,0278 & 0,0740 & 0,1068 \\
\hline & & $5,0 \mathrm{~L}$ & $\mathrm{~T} 7$ & 5 & 0,1978 & 0,4595 & 0,2855 \\
\hline & & $7,5 \mathrm{~L}$ & $\mathrm{~T} 8$ & 3 & 0,1087 & 0,2448 & 0,2228 \\
\hline \multirow{8}{*}{$\sum_{0}$} & \multirow{4}{*}{ 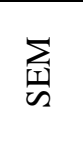 } & $0 \mathrm{~L}$ & T9 & 4 & 0,0600 & 0,1705 & 0,1230 \\
\hline & & $2,5 \mathrm{~L}$ & $\mathrm{~T} 10$ & 3 & 0,0304 & 0,0902 & 0,0821 \\
\hline & & $5,0 \mathrm{~L}$ & $\mathrm{~T} 11$ & 5 & 0,0616 & 0,1816 & 0,1129 \\
\hline & & $7,5 \mathrm{~L}$ & $\mathrm{~T} 12$ & 2 & 0,0106 & 0,0332 & 0,0478 \\
\hline & \multirow{4}{*}{$\sum_{0}$} & $0 \mathrm{~L}$ & T13 & 3 & 0,0315 & 0,0920 & 0,0838 \\
\hline & & $2,5 \mathrm{~L}$ & $\mathrm{~T} 14$ & 4 & 0,0650 & 0,1751 & 0,1263 \\
\hline & & $5,0 \mathrm{~L}$ & $\mathrm{~T} 15$ & 2 & 0,0783 & 0,1705 & 0,2460 \\
\hline & & $7,5 \mathrm{~L}$ & $\mathrm{~T} 16$ & 5 & 0,0886 & 0,2386 & 0,1482 \\
\hline \multirow{2}{*}{\multicolumn{2}{|c|}{ Período }} & \multirow{2}{*}{\multicolumn{2}{|c|}{$\begin{array}{c}\text { Chuvoso } \\
\text { Seco }\end{array}$}} & 15 & 0,3200 & 0,7709 & 0,2847 \\
\hline & & & & 9 & 0,0578 & 0,1739 & 0,0791 \\
\hline
\end{tabular}

${ }^{1}$ Fatores: Cons $(\mathrm{C})=$ consórcio $(\mathrm{sem}=0$ e com $=1)$; $\operatorname{cob}(\mathrm{C})=$ cobertura $(\mathrm{sem}=0$ e com $=1)$ e; bio $(\mathrm{B})=$ doses de biofertilizante de esterco $\left(0,0 ; 2,5 ; 5,0\right.$ e 7,5 L). ${ }^{2}$ Tratamentos: $\mathrm{T}_{1}=\mathrm{C}_{0} \mathrm{C}_{0} \mathrm{~B}_{0 \mathrm{~L}} ; \mathrm{T}_{2}=\mathrm{C}_{0} \mathrm{C}_{0} \mathrm{~B}_{2,5 \mathrm{~L}} ; \mathrm{T}_{3}=\mathrm{C}_{0} \mathrm{C}_{0} \mathrm{~B}_{5,0 \mathrm{~L}} ; \mathrm{T}_{4}=\mathrm{C}_{0} \mathrm{C}_{0} \mathrm{~B}_{7,5 \mathrm{~L}} ; \mathrm{T}_{5}=\mathrm{C}_{0} \mathrm{C}_{1} \mathrm{~B}_{0 \mathrm{~L}} ; \mathrm{T}_{6}=\mathrm{C}_{0} \mathrm{C}_{1} \mathrm{~B}_{2,5 \mathrm{~L}} ; \mathrm{T}_{7}=$ $\mathrm{C}_{0} \mathrm{C}_{1} \mathrm{~B}_{5,0 \mathrm{~L}} ; \mathrm{T}_{8}=\mathrm{C}_{0} \mathrm{C}_{1} \mathrm{~B}_{7,5 \mathrm{~L}} ; \mathrm{T}_{9}=\mathrm{C}_{1} \mathrm{C}_{0} \mathrm{~B}_{0 \mathrm{~L}} ; \mathrm{T}_{10}=\mathrm{C}_{1} \mathrm{C}_{0} \mathrm{~B}_{2,5 \mathrm{~L}} ; \mathrm{T}_{11}=\mathrm{C}_{1} \mathrm{C}_{0} \mathrm{~B}_{5,0 \mathrm{~L}} ; \mathrm{T}_{12}=\mathrm{C}_{1} \mathrm{C}_{0} \mathrm{~B}_{7,5 \mathrm{~L}} ; \mathrm{T}_{13}=\mathrm{C}_{1} \mathrm{C}_{1} \mathrm{~B}_{0 \mathrm{~L}} ; \mathrm{T}_{14}=\mathrm{C}_{1} \mathrm{C}_{1} \mathrm{~B}_{2,5 \mathrm{~L}} ; \mathrm{T}_{15}=\mathrm{C}_{1} \mathrm{C}_{1} \mathrm{~B}_{5,0 \mathrm{~L}} ;$ $\mathrm{T}_{16}=\mathrm{C}_{1} \mathrm{C}_{1} \mathrm{~B}_{7,5 \mathrm{~L}}$.

Fonte: Autores.

$\mathrm{Na}$ Tabela 2 é possível verificar, na linha período, que a riqueza de ordens foi maior no período chuvoso $(\mathrm{S}=15)$ em comparação ao período seco $(S=9)$. Ou seja, foram encontradas 15 ordens da macrofauna epigeica no período chuvoso e 9 ordens no período seco.

Diante disso, é provável que o aumento sazonal esteja relacionado ao desenvolvimento de ambientes mais favoráveis para os diferentes grupos da fauna, promovendo maior riqueza de ordens no período de chuvas, ao passo em que uma maior abundância da fauna no período seco pode ter reduzido a diversidade, visto que, quanto maior a densidade da fauna do solo em determinados ambientes - em especial sistemas de cultivo - maiores serão as hipóteses de predominância de algum 
grupo, reduzindo, com isso, a diversidade (Silva et al., 2012). O estudo de Moço et al. (2005) mostrou que o aumento nos índices de chuva resultou em maior disponibilidade de recursos, o que criou microambientes mais favoráveis à fauna edáfica.

Ainda na Tabela 2, entre os tratamentos, o maior valor para riqueza $(S=9)$ foi encontrado na presença de consórcio e dose de 2,5 L de biofertilizante de esterco bovino, no período chuvoso (T10); na fase seca, o maior valor $(\mathrm{S}=5)$ foi encontrado mais disperso, ocorrendo na presença e ausência de biofertilizante e/ou consórcio e/ou cobertura (T1, T2, T4, T7, T11 e T16). Essa resposta indica que a utilização destes métodos de manejo aliados à disponibilidade hídrica promove maior riqueza de ordens e, com isso, maior equilíbrio do agroecossistema.

Entre os índices de diversidade (Tabela 2), na primeira época de amostragem, os maiores valores para índices de Simpson $\left(D_{S}\right)$ e equitabilidade de Pielou $(J)$ foram encontrados para à presença de consórcio (T9) e o índice de ShannonWiener $(H)$ apresentou maior valor para a presença de consórcio e dose de 2,5 L de biofertilizante de esterco bovino (T10). Na segunda época de amostragem, os maiores valores para todos os índices de diversidade foram encontrados para o tratamento referente à presença de cobertura e dose de 5,0 L de biofertilizante bovino (T7).

A resposta destes índices reafirma a importância de métodos de manejo que priorizam a qualidade do solo, pois esses influenciam, positivamente, a diversidade da macrofauna epiedáfica no agroecossistema, contribuindo para maior complexidade, equilíbrio ambiental e consequente produtividade.

De acordo com Moço et al. (2005), coberturas vegetais diversas proporcionam maior heterogeneidade da serrapilheira, influenciando, com isso, a diversidade da fauna, além de gerar um micro habitat que permitirá a colonização de diferentes espécies que possuem distintas estratégias de sobrevivência, trazendo equilíbrio ao agroecossistema. Para Silva et al. (2012), este ambiente confere maior disponibilidade de alimento, amplitudes térmicas mais baixas e condições químicas e microbiológicas apropriadas à sobrevivência destes organismos no solo.

Esse resultado aponta, ainda, para a influência do biofertilizante de esterco bovino sobre estes grupos, visto que suas propriedades criam condições oportunas à fauna, por proporcionarem melhorias na fertilidade do solo, em especial nas camadas superficiais, sobretudo dos nutrientes com menor mobilidade (Nunes et al., 2009; Sá et al., 2015; Moraes, Ferreira, \& Borges, 2016; Maciel et al., 2019), o que favorece a fragmentação dos resíduos pelos organismos edáficos. Este apontamento é ratificado pelo estudo de Cherubin et al. (2015), os quais constataram que a maior dose de dejeto líquido suíno proporcionou maior número de grupos, riqueza de Margalef e diversidade de Shannon da fauna edáfica de um Latossolo Vermelho com diferentes sistemas de manejo.

Foram encontradas diferenças significativas entre os períodos de coleta $(\mathrm{p}<0,01)$ e na interação entre consórcio e cobertura $(\mathrm{p}<0,05)$ (Tabela 3$)$. 
Tabela 3 - Resumo da análise de variância, pelo quadrado médio, referente macrofauna epiedáfica na área cultivada com noni sob consórcio (sem e com), cobertura (sem e com) e doses de biofertilizante de esterco bovino (0,0;2,5; 5,0 e 7,5 L) no período chuvoso e seco, Bananeiras-PB, CCHSA, Brasil, 2020.

\begin{tabular}{lcc}
\hline Fontes de Variação & GL & Quadrado Médio \\
\hline Bloco & 2 & $1,9^{\text {ns }}$ \\
Consórcio (Cons) & 1 & $21,0^{\mathrm{ns}}$ \\
Cobertura (Cob) & 1 & $22,4^{\mathrm{ns}}$ \\
Doses (D) & 3 & $0,8^{\mathrm{ns}}$ \\
Períodos (P) & 1 & $82,6^{* * *}$ \\
Interação Cons x Cob & 1 & $37,4^{*}$ \\
Interação Cons x D & $3,6^{\mathrm{ns}}$ \\
Interação Cob x D & 3 & $0,5^{\mathrm{ns}}$ \\
Interação Cons x P & 3 & $2,1^{\mathrm{ns}}$ \\
Interação Cob x P & 1 & $10,8^{\mathrm{ns}}$ \\
Interação D x P & 1 & $1,9^{\mathrm{ns}}$ \\
Interação Cons x Cob x D & 3 & $13,8^{\mathrm{ns}}$ \\
Interação Cons x Cob x P & 3 & $0,0^{\mathrm{ns}}$ \\
Interação Cons x D x P & 1 & $2,3^{\mathrm{ns}}$ \\
Interação Cob x D x P & $3,0^{\mathrm{ns}}$
\end{tabular}

Consórcio

\begin{tabular}{lr}
\hline Sem & $49,35 \pm 54,46^{\mathrm{a}}$ \\
Com & $36,35 \pm 31,50^{\mathrm{a}}$ \\
\hline
\end{tabular}

\section{Cobertura}

\begin{tabular}{lc}
\hline Sem & $51,71 \pm 56,58^{\mathrm{a}}$ \\
Com & $34,00 \pm 26,14^{\mathrm{a}}$ \\
\hline Doses (L) & $38,38 \pm 27,67^{\mathrm{a}}$ \\
\hline 0 & $39,29 \pm 27,05^{\mathrm{a}}$ \\
2,5 & $42,67 \pm 40,74^{\mathrm{a}}$ \\
5 & $51,08 \pm 70,74^{\mathrm{a}}$ \\
7,5 & \\
\hline
\end{tabular}

Período

Seco

$56,56 \pm 57,62^{\mathrm{a}}$

Chuvoso

$29,15 \pm 18,45^{\mathrm{b}}$

Média

44,73

ns, ***, * respectivamente, não significativos, significativo a p<0,0001, e p<0,05; CV: coeficiente de variação; GL: grau de liberdade. ${ }^{A, B}$ Médias seguidas por diferentes letras maiúsculas diferem de acordo com o teste $\mathrm{F}(\mathrm{P}<0,05)$.

Fonte: Autores.

Na Tabela 3 é possível visualizar na linha período que a maior média foi encontrada na fase seca, o que já era esperado, visto que a abundância foi predominantemente maior nesta época.

No desdobramento da interação entre consórcio e cobertura, é evidente que as maiores médias para abundância da macrofauna epiedáfica foram encontradas na ausência de cobertura e na presença de consórcio (Figura 3). 
Figura 3 - Macrofauna epiedáfica da área cultivada com noni sob consórcio (sem e com), cobertura (sem e com) e doses de biofertilizante de esterco bovino (0,0; 2,5; 5,0 e 7,5 L) no período chuvoso e seco, CCHSA, Bananeiras-PB, Brasil, 2020.

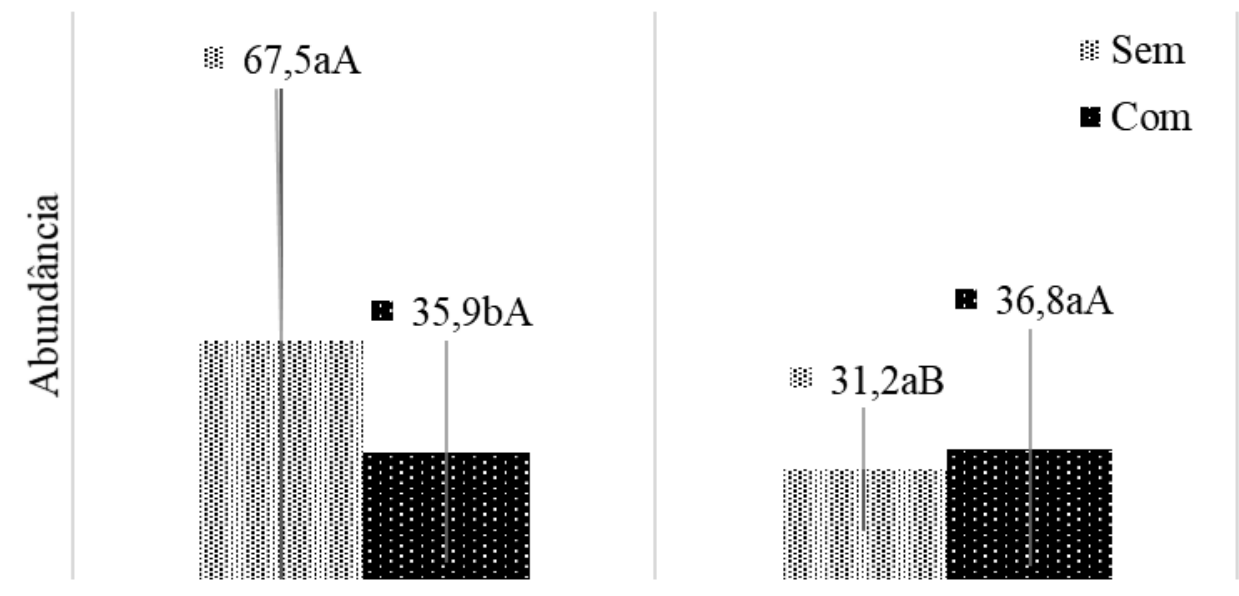

Cobertura x Consórcio

${ }^{\mathrm{a}, \mathrm{b}}$ Médias seguidas por diferentes letras minúsculas diferem de acordo com o teste $\mathrm{F}(\mathrm{P}<0,05)$ para cada cobertura.

A,B Médias seguidas por diferentes letras maiúsculas diferem de acordo com o teste $\mathrm{F}(\mathrm{P}<0,05)$ para cada consórcio.

Fonte: Autores.

$\mathrm{Na}$ Figura 3, portanto, verifica-se que as médias para cobertura e consórcio diferiram de acordo com o teste $\mathrm{F}$ $(\mathrm{P}<0,05)$ com maior valor para ausência de cobertura $(67,5)$, e presença de consórcio $(36,8)$.

A ausência de cobertura pode ter atraído organismos mais específicos da fauna, por ser um ambiente de menor complexidade biológica e reduzida competição, induzindo a uma menor diversidade e maior abundância, inferindo que sistemas de cultivo que utilizam poucos ou apenas um método de manejo pode reduzir a qualidade do ambiente.

Já a presença de consórcio pode ter promovido um ambiente mais complexo, que embora possa apresentar maior competição entre espécimes, induziu a uma maior abundância de diferentes organismos, corroborando com Silva et al. (2013, p. 135), que observaram que o uso de consórcios entre culturas de cobertura promoveu o aumento da abundância de indivíduos, em especial colêmbolos.

No método de agrupamento, foi aplicado o algoritmo de médias ponderadas (UpgMA) por meio do coeficiente de Jaccard. Os resultados encontrados para Jaccard se integram na escala de 0 a 1 . Dessa forma, a similaridade aumenta quanto mais próximo o valor estiver de 1, gerando um resultado que é expresso na forma de dendrograma.

A Figura 4 apresenta o resultado da análise de agrupamento (uPGMA), tendo como referência o Quociente de Jaccard. 
Figura 4 - Dendrograma de similaridade faunística obtido por uma matriz de presença/ausência das espécies presentes nos 16 tratamentos $^{1}$, utilizando o método de médias ponderadas por grupo (uPGMA) e o Quociente de Jaccard no período chuvoso (A) e $\operatorname{seco}(B)$.
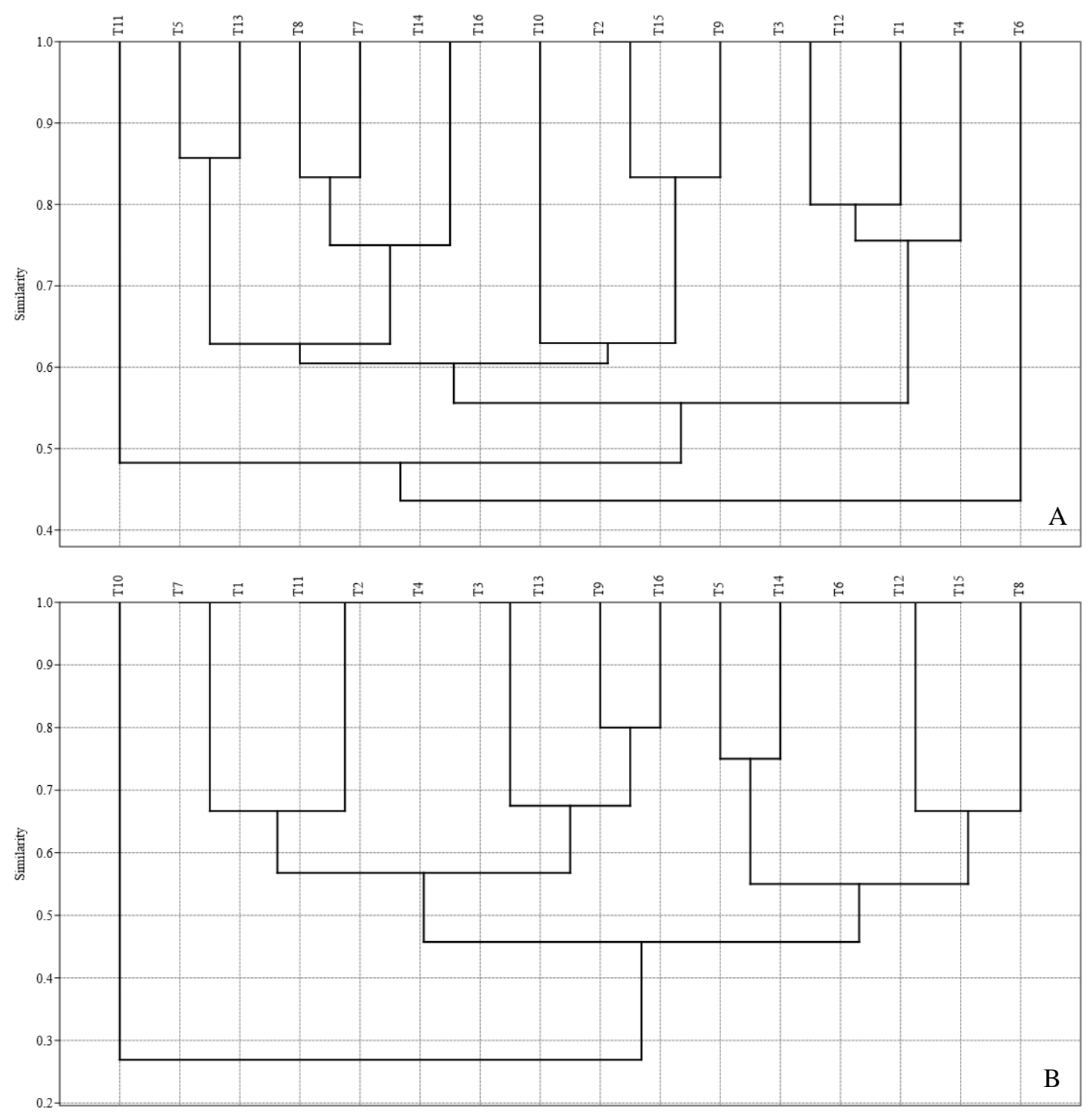

*Tratamentos: CONS $(\mathrm{C})=$ consórcio $(\mathrm{sem}=0$ e com $=1)$; COB $(\mathrm{C})=$ cobertura $($ sem $=0$ e com $=1)$ e; $\mathrm{BIO}$ (B) = níveis de biofertilizante de esterco bovino $(0,0 ; 2,5 ; 5,0$ e 7,5 L);

${ }^{1}$ Tratamentos: $\mathrm{T}_{1}=\mathrm{C}_{0} \mathrm{C}_{0} \mathrm{~B}_{0 \mathrm{~L}} ; \mathrm{T}_{2}=\mathrm{C}_{0} \mathrm{C}_{0} \mathrm{~B}_{2,5 \mathrm{~L}} ; \mathrm{T}_{3}=\mathrm{C}_{0} \mathrm{C}_{0} \mathrm{~B}_{5,0 \mathrm{~L}} ; \mathrm{T}_{4}=\mathrm{C}_{0} \mathrm{C}_{0} \mathrm{~B}_{7,5 \mathrm{~L}} ; \mathrm{T}_{5}=\mathrm{C}_{0} \mathrm{C}_{1} \mathrm{~B}_{0 \mathrm{~L}} ; \mathrm{T}_{6}=\mathrm{C}_{0} \mathrm{C}_{1} \mathrm{~B}_{2,5 \mathrm{~L}} ; \mathrm{T}_{7}=$ $\mathrm{C}_{0} \mathrm{C}_{1} \mathrm{~B}_{5,0 \mathrm{~L}} ; \mathrm{T}_{8}=\mathrm{C}_{0} \mathrm{C}_{1} \mathrm{~B}_{7,5 \mathrm{~L}} ; \mathrm{T}_{9}=\mathrm{C}_{1} \mathrm{C}_{0} \mathrm{~B}_{0 \mathrm{~L}} ; \mathrm{T}_{10}=\mathrm{C}_{1} \mathrm{C}_{0} \mathrm{~B}_{2,5 \mathrm{~L}} ; \mathrm{T}_{11}=\mathrm{C}_{1} \mathrm{C}_{0} \mathrm{~B}_{5,0 \mathrm{~L}} ; \mathrm{T}_{12}=\mathrm{C}_{1} \mathrm{C}_{0} \mathrm{~B} 7,5 \mathrm{~L} ; \mathrm{T}_{13}=\mathrm{C}_{1} \mathrm{C}_{1} \mathrm{~B}_{0 \mathrm{~L}} ; \mathrm{T}_{14}=$ $\mathrm{C}_{1} \mathrm{C}_{1} \mathrm{~B}_{2,5 \mathrm{~L}} ; \mathrm{T}_{15}=\mathrm{C}_{1} \mathrm{C}_{1} \mathrm{~B}_{5,0 \mathrm{~L}} ; \mathrm{T}_{16}=\mathrm{C}_{1} \mathrm{C}_{1} \mathrm{~B}_{7,5 \mathrm{~L}}$.

Fonte: Autores.

Considerando um nível de corte de 50\% no eixo da escala do dendrograma, na Figura 4A, os tratamentos estudados foram divididos em 3 grupos no período chuvoso. O grupo 1 é aquele composto pelo fragmento 6, o grupo 2 compreende o fragmento 11, o grupo 3 é composto pelos fragmentos 1, 3, 4, 12, 5, 13, 8, 7, 14, 16, 10, 2, 15 e 9.

É importante destacar na Figura 4A que os grupos 1 e 2 se distanciaram em maior nível do grupo 3, provavelmente por apresentarem menores valores para riqueza e diversidade de ordens encontradas. Os fragmentos do grupo 3 apresentaram maior similaridade, certamente, em razão da semelhança que compartilham entre os valores de riqueza e diversidade de ordens, os quais foram maiores em comparação aos grupos 1 e 2 .

No período seco, Figura 4B, considerando um nível de corte de 50\%, pode-se dividir 3 grupos, sendo o grupo 1 composto pelo tratamento 10 , o grupo 2 pelos tratamentos $5,14,6,12,15$ e 8 e o grupo 3 pelos tratamentos $7,1,11,2,4,3,13$, 
9 e 16. O tratamento correspondente ao grupo 1 apresentou valores medianos para riqueza e diversidade de ordens, já o grupo 2 apresentou menores valores para riqueza e diversidade nos tratamentos referentes e o grupo 3 os maiores valores, justificando, assim, a divisão dos grupos e suas dissimilaridades.

$\mathrm{Na}$ correlação realizada entre as ordens da macrofauna epiedáfica e os atributos químicos do solo (Tabela 4), foi verificada correlação positiva significativa entre espécimes da ordem Diptera e teores de matéria orgânica.

Tabela 4 - Correlação linear entre macrofauna epiedáfica e matéria orgânica do solo.

\begin{tabular}{cc}
\hline Ordem da Macrofauna Epiedáfica & Atributo Químico \\
\cline { 2 - 2 } Diptera & M.O.S. \\
\hline & $0,34^{*}$ \\
\hline
\end{tabular}

M.O.S: matéria orgânica do solo.

*: correlação significativa a $5 \%$ de probabilidade pelo teste $\mathrm{t}$.

Fonte: Autores.

De acordo com a Tabela 4 verifica-se a correlação linear positiva significativa a 5\% de acordo com o teste t entre Diptera e a matéria orgânica do solo, e esse resultado, provavelmente, está relacionado as larvas que várias famílias de Diptera depositam em áreas, onde há elevada concentração de matéria orgânica, conforme apontam Rosa et al. (2015). De acordo com estes autores, as larvas terrestres desses insetos se associam, em especial, à decomposição de matéria orgânica vegetal e animal nos sistemas florestais e agrícolas, contudo, também existem os grupos que usam resíduos vegetais em decomposição no solo ou em raízes de plantas vivas, em algum momento de seu ciclo de vida. Dessa forma, essa resposta indica elevados teores de material orgânico no solo estudado.

\section{Conclusões}

A ordem Hymenoptera, representada basicamente por exemplares da família Formicidae, foi a mais abundante nas duas épocas de coleta.

No período chuvoso, $D_{S}$ e $J$ foram maiores na presença de consórcio, e $H$ foi maior na presença de consórcio e dose de 2,5 L de biofertilizante de esterco bovino. No período seco, $D_{S}, J$ e $H$ foram maiores para à presença de cobertura e dose de 5,0 L de biofertilizante.

A diversidade e riqueza de ordens da macrofauna epiedáfica se mostrou uma importante ferramenta de bioindicação de distúrbios e de qualidade do solo em uma área de noni sob diferentes práticas de manejo em duas épocas de coleta.

O uso de práticas de manejo conservacionistas integradas, como o uso do biofertilizante de esterco bovino associado ao consórcio com outras culturas e cobertura morta, proporcionam condições mais favoráveis a uma maior diversidade de ordens da macrofauna epiedáfica, em comparação com áreas que utilizam apenas um método de manejo.

A macrofauna epiedáfica é um importante indicador biológico para avaliação de sistemas agrícolas sustentáveis.

Para trabalhos futuros, sugere-se o uso destes procedimentos em diferentes regiões com importância econômica para fins de comparação, bem como a utilização de outros métodos de coleta da fauna edáfica que forneçam uma perspectiva mais integrada da qualidade dos solos, como monólitos de solo e funis de Berlese-Tüllgren.

\section{Agradecimentos}

Universidade Federal da Paraíba e Coordenação de Aperfeiçoamento de Pessoal de Nível Superior. 


\section{Referências}

Alonso, J. D. S., Duarte, L. C., Barrigossi, J. A. F., \& Didonet, A. D. (2017). Sistema Agroflorestal com Feijão e Milho sob Manejo Agroecológico: Entomofauna e Aranhas Associadas. Boletim de Pesquisa e Desenvolvimento, (48), 28.

Aquino, A. M., Aguiar-Menezes, E. D. L., \& Queiroz, J. M. (2006). Recomendações para coleta de artrópodes terrestres por armadilhas de queda (" PitfallTraps"). Embrapa Agrobiologia-Circular Técnica (INFOTECA-E).

Baretta, D., Santos, J. C. P., Segat, J. C., Geremia, E. V., Oliveira Filho, L. D., \& Alves, M. V. (2011). Fauna edáfica e qualidade do solo. Tópicos em ciência do solo, 7, 119-170.

Brown, G. G., Niva, C. C., Zagatto, M. R. G., Ferreira, S. D. A., Nadolny, H. S., Cardoso, G. B. X., \& Sautter, K. D. (2015). Biodiversidade da fauna do solo e sua contribuição para os serviços ambientais. Embrapa Florestas-Capítulo em livro científico (ALICE).

Cabrera, G. (2012). La macrofauna edáfica como indicador biológico del estado de conservación/perturbación del suelo. Resultados obtenidos en Cuba. Pastos y forrajes, 35(4), 346-363.

Cherubin, M. R., Eitelwein, M. T., Fabbris, C., Weirich, S. W., Silva, R. F. D., Silva, V. R. D., \& Basso, C. J. (2015). Qualidade física, química e biológica de um Latossolo com diferentes manejos e fertilizantes. Revista Brasileira de Ciência do solo, 39(2), 615-625.

Correia, M. E. F. (2002). Relações entre a diversidade da fauna de solo e o processo de decomposição e seus reflexos sobre a estabilidade dos ecossistemas. Embrapa Agrobiologia-Documentos (INFOTECA-E).

Crepaldi, R. A., Portilho, I. I. R., Silvestre, R., \& Mercante, F. M. (2014). Formigas como bioindicadores da qualidade do solo em sistema integrado lavourapecuária. Ciência Rural, 44(5), 781-787.

Dantas, J. O., Santos, M. J. C. D., Santos, F. R., Pereira, T. P. B., Oliveira, A. V. S., Araújo, C. C., \& Rita, M. R. (2012). Levantamento da entomofauna associada em sistema agroflorestal. Scientia plena, 8(4).

Figueiredo, E. O. (2001). Reflorestamento com teca (Tectona grandis LF) no estado do Acre. Embrapa Acre-Documentos (INFOTECA-E).

Hammer, O., Harper, D. A., \& Ryan, P. D. (2001). Palaeontological statistics software package for education and data analysis. Palaeontologia Electronica, 4(1)

Lavelle, P., \& Spain, A. V. (2001). Soil ecology. Springer Science \& Business Media.

Lima, K. D. R. D., Camara, R., Chaer, G. M., Pereira, M. G., \& Resende, A. S. D. (2017). Soil fauna as bioindicator of recovery of degraded areas in the Caatinga biome. Revista Caatinga, 30(2), 401-411.

Ludwig, R. L., Pizzani, R., Schaefer, P. E., Goulart, R. Z., \& Lovato, T. (2012). Efeito de diferentes sistemas de uso do solo na diversidade da fauna edáfica na região central do Rio Grande do Sul. Enciclopédia Biosfera, 8(14), 485-495.

Maciel, A. M., Silva, J. B. G., de Matos Nascimento, A., de Paula, V. R., \& Otenio, M. H. (2019). Aplicação de biofertilizante de bovinocultura leiteira em um planossolo. Revista em Agronegócio e Meio Ambiente, 12(1), 151-171.

Martínez, P. A. (2016, May). Ácaros oribátidos en ambientes semiáridos de Argentina. Su potencial bioindicador. In proceedings II congreso latinoamericano de acarología (p. 31).

Moço, M. K. D. S., Gama-Rodrigues, E. F. D., Gama-Rodrigues, A. C. D., \& Correia, M. E. F. (2005). Caracterização da fauna edáfica em diferentes coberturas vegetais na região norte fluminense. Revista Brasileira de Ciência do Solo, 29(4), 555-564.

Moraes, A. D. S., Ferreira, N. D. S., \& Borges, W. (2016). Efeito da aplicação de biofertilizante sobre o solo. In Embrapa Amapá-Resumo em anais de congresso (ALICE). In: Jornada Científica da Embrapa Amapá, 2, 2016, Embrapa Amapá.

Noguera-Talavera, Á., Reyes-Sánchez, N., Mendieta-Araica, B., \& Salgado-Duarte, M. M. (2017). Macrofauna edáfica como indicador de conversión agroecológica de un sistema productivo de Moringa oleifera Lam. en Nicaragua. Pastos y Forrajes, 40(4), $184-187$.

Nunes, L. A. P. L., da Silva, D. I. B., de Araújo, A. S. F., Leite, L. F. C., \& Correia, M. E. F. (2012). Caracterização da fauna edáfica em sistemas de manejo para produção de forragens no Estado do Piauí. Revista Ciência Agronômica, 43(1), 30-37.

Nunes, J. C., Cavalcante, L. F., Rebequi, A. M., Lima Neto, A., Diniz, A. A., Silva, J. J. M., \& Brehm, M. D. S. (2009). Formação de mudas de noni sob irrigação com águas salinas e biofertilizante bovino no solo. Engenharia Ambiental, 6(2), 451-463.

Oliveira Filho, L. C. I., Klauberg Filho, O., Baretta, D., Tanaka, C. A. S., \& Sousa, J. P. (2016). Collembola community structure as a tool to assess land use effects on soil quality. Revista Brasileira de Ciência do Solo, 40, 1-18.

Pereira, K. D. S., \& Carvalho, R. D. S. (2011). 10723-Entomofauna do solo de mata primária Atlântica como padrão indicador de qualidade do agroecossistema. Cadernos de Agroecologia, 6(2), 1.

Pereira, A. S., Shitsuka, D. M., Parreira, F. J., \& Shitsuka, R. (2018). Metodologia da pesquisa científica. UFSM, NTE. E-book. https://repositorio.ufsm.br/bitstream/handle/1/15824/Lic_Computacao_Metodologia-Pesquisa-Cientifica.pdf?sequence=1.

Pielou, E. C. (1975). Ecological diversity. John Wiley \& Sons.

Pompeo, P. N., Oliveira Filho, L. C. I., Klauberg Filho, O., Mafra, Á. L., Baretta, C. R. D. M., \& Baretta, D. (2016). Diversidade de Coleoptera (Arthropoda: Insecta) e atributos edáficos em sistemas de uso do solo no Planalto Catarinense. Scientia agraria, 17(1), 16-28. 
Research, Society and Development, v. 10, n. 1, e20610111664, 2021 (CC BY 4.0) | ISSN 2525-3409 | DOI: http://dx.doi.org/10.33448/rsd-v10i1.11664

Prado, E. P., \& Castro, M. T. (2017). Diversidade de insetos em áreas de produção orgânica de hortaliças próximas a um sistema agroflorestal no distrito federal. Biodiversidade, 16 (2).

Rodrigues, D. M., Ferreira, L. O., da Silva, N. R., dos Santos Guimarães, E., Martins, I. C. F., \& de Assis Oliveira, F. (2016). Diversidade de artrópodes da fauna edáfica em agroecossistemas de estabelecimento agrícola familiar na Amazônia Oriental. Revista de Ciências Agrárias Amazonian Journal of Agricultural and Environmental Sciences, 59(1), 32-38.

Rosa, M. G. D., Klauberg Filho, O., Bartz, M. L. C., Mafra, Á. L., Sousa, J. P. F. A. D., \& Baretta, D. (2015). Macrofauna edáfica e atributos físicos e químicos em sistemas de uso do solo no planalto catarinense. Revista Brasileira de Ciência do Solo, 39(6), 1544-1553.

Sá, F. V. S., Mesquita, E. F., Costa, J. D., Bertino, A. M. P., \& Araújo, J. L. (2015). Influência do gesso e biofertilizante nos atributos químicos de um solo salino-sódico e no crescimento inicial do girassol. Irriga, 20(1), 46-59.

Santos, R. S., da Silva, D. A., Pereira, A. A. A., \& de Oliveira, L. C. (2016). Levantamento da entomofauna edáfica associada à mata ripária e sistema agroflorestal em Rio Branco, AC. Embrapa Acre-Artigo em periódico indexado (ALICE).

Silva, J., Jucksch, I., Maia, C. I., Feres, A., \& de Castro Tavares, R. (2012). Fauna do solo em sistemas de manejo com café. Journal of Biotechnology and Biodiversity, 3(2), 59-71.

Silva, R. F. D., Corassa, G. M., Bertollo, G. M., Santi, A. L., \& Steffen, R. B. (2013). Fauna edáfica influenciada pelo uso de culturas e consórcios de cobertura do solo. Pesquisa Agropecuária Tropical, 43(2), 130-137.

Shannon, C. E., \& Weaver, W. (1949). A mathematical model of communication. Urbana, IL: University of Illinois Press, 11.

Simpson, E. H. (1949). Measurement of diversity. Nature, 163(4148), 688-688.

Socarrás, A. (2013). Mesofauna edáfica: indicador biológico de la calidad del suelo. Pastos y Forrajes, 36(1), 5-13. 